\title{
Appraisal of Urban Heat Island and Its Impacts on Environment Using Landsat TM in Peshawar, Pakistan
}

\author{
Rashid Mehmood', Muhammad Atif Butt' ${ }^{1}$, Syed Amer Mahmood ${ }^{1}$, Farhan Ali ${ }^{2}$ \\ ${ }^{1}$ Department of Space Sciences, University of the Punjab, Lahore, Pakistan \\ ${ }^{2}$ College of Earth \& Environmental Sciences, University of the Punjab, Lahore, Pakistan \\ Email: rashidmhmood@yahoo.com
}

How to cite this paper: Mehmood, R., Butt, M.A., Mahmood, S.A. and Ali, F. (2017) Appraisal of Urban Heat Island and Its Impacts on Environment Using Landsat TM in Peshawar, Pakistan. Advances in Remote Sensing, 6, 192-200.

https://doi.org/10.4236/ars.2017.63014

Received: July 19, 2017

Accepted: September 3, 2017

Published: September 6, 2017

Copyright $\odot 2017$ by authors and Scientific Research Publishing Inc. This work is licensed under the Creative Commons Attribution International License (CC BY 4.0).

http://creativecommons.org/licenses/by/4.0/

\begin{abstract}
Last couple of decades witnessed a rapid escalation in urban temperature of Peshawar city and its neighboring localities. This alarming condition gave birth to climatic term Urban Heat Island (UHI) created drastic alteration in surface temperatures. In this study, thermal infrared remote sensing data has been employed to map out and monitor such micro-climatic variation in temperatures in land use/land cover exposed surface to the environment. To assess these outcomes resulting from human activities, Landsat TM data band 6 was subjected through ERDAS Imagine 2013. For further processing, ARC GIS helped a lot in making maps to pinpoint the heat island in and around the city. Moreover, a relationship of land surface temperature with urban sprawl, environmental and industrialization was established. This study has shown a substantial upsurge in temperature about 1 to 3 degrees. Urban sprawl and industrialization at the edges are accounting for these conditions. Urban and industrial data has also reinforced the fact being drawn from remotely sensed data. Hence, evaluation of Land surface temperature data captured through remote satellite has proven to be effective tool not only for monitoring and analyzing temperature but also for assessing its adverse impacts on the environment and climate.
\end{abstract}

\section{Keywords}

Land Surface Temperature, Urban Heat Island, Thermal Infrared, Landsat TM

\section{Introduction}

LST is the measure of heat emitted from land surface due to numerous activities 
connected with the land surface. Upsurge in paved land cover is an indication of intense human activities, which often leads to increased LSTs [1]. Amplified LST in certain urban sacks in comparison to its surroundings subsequent to the increase in cement surfaces is known as urban heat island (UHI) phenomenon [2]. Urban Heat Island (UHI) formation and heating effect in urban is a property associated with urban and land transformation that is the key interest in scientific disciplines. This is because UHI signal gives insight about land surface changes occurring due to human activities. It casts drastic impact on human health, ecosystem function, weather and climate in the long run. All the negative impacts happen as a result of reduction in latent heat flux and also increase in sensible heat in a populated area. Hence, changes in albedo occur by all the factors. It brings about temperature a differential phenomenon which was referred as Urban Heat Island (UHI) by Manley [3] and later on effort on urban area has been started on both air and surface temperature estimation [4]. Thermal infrared image is a prime source of information to mark the surface heat islands [5].

Temperature map can be drawn from time series imageries of the same resolution. It reveals a drastic results depicting 1 to 3 degree upsurge in Peshawar city. This situation can be lethal and challenge the efforts being made for provision of quality foods, health facilities, housing, education and adequate infrastructure to common people.

Remote sensing and GIS has developed such techniques to monitor the rise in urban temperature that is now possible with thermal imagery captured through the Landsat TM sensor. Land surface temperature (LST) estimation is handy analysis in projecting future trends in terms of temperatures. Spatio-temporal data were used to develop models of land surface atmosphere exchange, and to analyze the relationship between temperature and land use and land cover (LULC) in urban areas [6]. This goal was achieved through time series imagery used before for urban sprawl mapping and change detection. Remotely sensed data was subjected through Landsat TM spatial temperature graphical model (.gmd format) in ERDAS 2013 software. Output showed the spatial temperature variation in gray scales. For thematic mapping, it was further processed in ARC GIS which displayed more clear and sharp changes in temperatures (Celsius). Such implication requires the imagery of the same spatial resolution as employed in this analysis.

\section{Aims and Objectives}

The aim of the current study is to monitor urban heat island (UHI) and temperature variations in Peshawar and its suburbs. Moreover, how much variation has taken place in temperatures during the span of 19 years.

Prime objectives of this research study are:

1. To classify the imagery for urban area identification and quantification

2. To process and calculate the thermal band for LST estimation

3. To map out both land use/land cover classification and surface tempera- 
tures

4. To compare and analyze the results of time series imagery

\section{Study Area}

Peshawar is largest and the capital city of the Khyber Pakhtunkhwa. To the west, The Federally Administered Tribal Areas (FATA) shares the boundary and Mohmand Agency located at its North. Similarly, Kohat district is on its Southern side. Charsadda and Nowshera link towards its North and North-East respectively. Moreover, Afghan boundary is just $40 \mathrm{Km}$ away from west of the city. Peshawar locates in between $44^{\circ} 15^{\prime}$ and $34^{\circ} 15^{\prime}$ North Latitude; $71^{\circ} 22^{\prime}$ and $71^{\circ} 42^{\prime}$ East Longitude. It spatially extends to 1257 square kilometers. Winter begins from the middle of Peshawar receives rainfall both in summer and winter. Western disturbances bring about severe winter rainfall, especially in the months of February and April. The March and August have witnessed highest winter and summer precipitation respectively. Comparatively, average winter rainfall is on the higher side than summer rainfall. In Peshawar, wind speed swings around 5 knots in December to 24 knots in hot June. In same way, the relative humidity fluctuates from $46 \%$ in June to $76 \%$ in August respectively [7].

Figure 1 explains the study area Geo-spatial presence starting from Pakistan
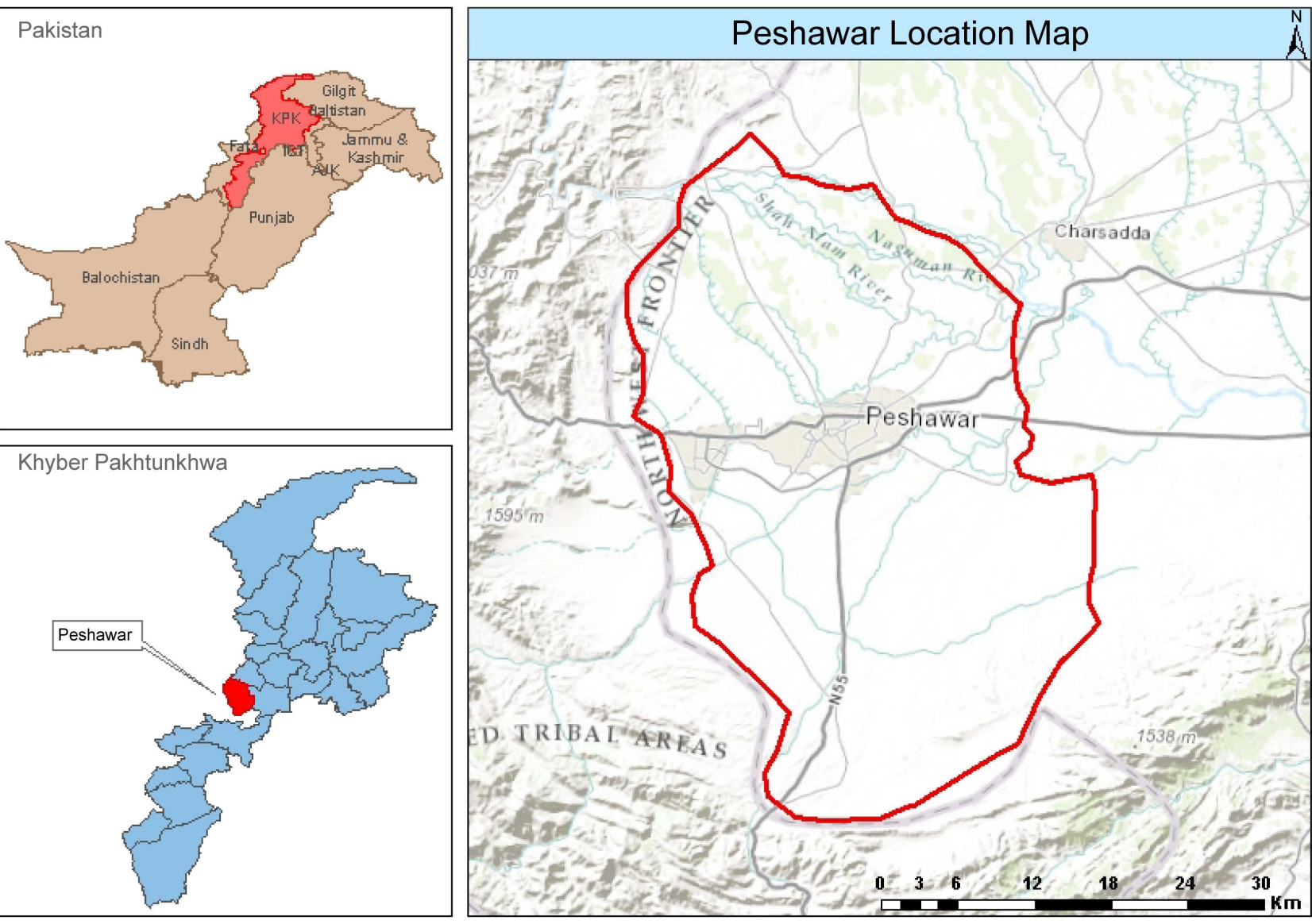

Figure 1. District Peshawar (Source: Urban Unit). 
Map and ending at the district level map shown on the terrain.

\section{Methodology}

Software used for this process was ERDAS Imagine 2013 and ARC GIS. LST process conducted in ERDAS Imagine 2013 which produced temperature distributed images. Later on, it subjected through ARC GIS for mapping. Landsat 5 TM sensor images were employed to estimate land surface temperature. Further, this data is used to estimate Land Surface Temperature (LST) from thermal data which was subjected through a conversion of digital number (DN) of pixel of image in spectral radiance by employing sensor calibration data [8]. The Landsat Thematic Mapper (TM) sensor acquires thermal data from radiation emitted from the Earth and save the information as a digital number (DN) with a range 0 to 255 in the thermal infrared band (band 6).

In the above Figure 2, all processes involve in the research is shown through a flow chart. Images from Landsat 5 TM Sensor are downloaded from Earth Explorer website of the United States Geological Survey (USGS). Images patches are extracted to get study area. After preparing images initial necessary steps radiometric and geometric corrected are applied to get refined imagery with no flaws in terms of visualization and calculation of areas while applying classifier algorithm. Radiometric corrected are then further extended to atmospheric correction to get imagery free from atmospheric effects. In the final stage following calculation are run by the software to produce a LST image.

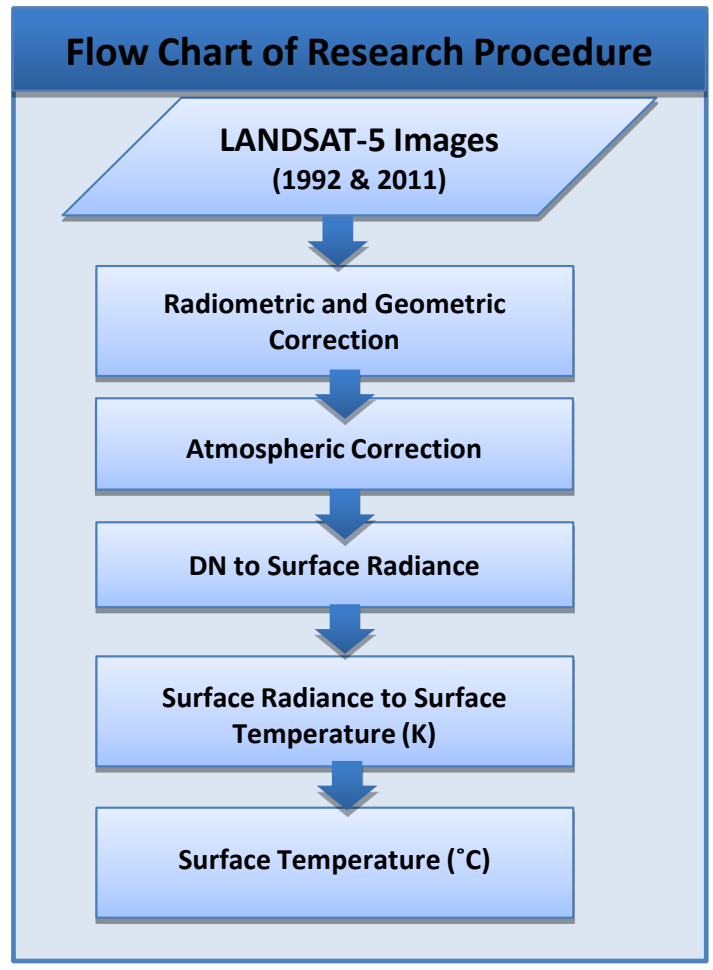

Figure 2. Flow chart of research procedure. 
LST may be calculated through a procedure explained below in three steps:

In the first step digital number (DN) values are converted into Spectral Radiance (L)

$$
\mathrm{L}=\mathrm{LMIN}+(\mathrm{LMAX}-\mathrm{LMIN}) * \mathrm{DN} / 255
$$

In this equation

L stands for Spectral Radiance

LMIN stands for Spectral Radiance of DN value 1

LMAX stands for Spectral Radiance of DN value 255

DN stands for Digital Number

In step 2 processes involve the conversion of Spectral Radiance to Temperature in Kelvin

$$
\mathrm{T}_{\mathrm{B}}=\frac{\mathrm{K}_{2}}{\ln \left(\mathrm{K}_{1} / \mathrm{L}+1\right)}
$$

Here

$\mathrm{K}_{2}$ is for Calibration Constant 1 (607.76)

$\mathrm{K}_{1}$ is for Calibration Constant 2 (1260.56)

$\mathrm{T}_{\mathrm{B}}$ is for Surface Temperature

In the third step, conversion of temperature from Kelvin to Celsius is calculated

$$
\mathrm{T}_{\mathrm{B}}=\mathrm{T}_{\mathrm{B}}-273
$$

While doing all these calculations, a few values like LMIN and LMAX can be drawn from the satellite header file.

\section{Results and Discussions}

The results from the above methodology are as follows:

Figure 3 shows urban area located in Peshawar and its outskirts.

The satellite image is classified into five major classes, Urban, Soil, Rock, Vegetation and Water. After supervised classification, above spatial distribution of these classes can be seen clearly. From this pattern, temperature variation can be observed through Landsat TM time series imagery by employing Land Surface Temperature.

Figure 4 exhibits land use area covered in Square kilometers in 2011.

Figure 5 shows highest maximum air temperature during the period of 1931 to 2012 .

Above statistical facts and figures of climate drawn from various instruments and sources may also be verified through remote sensing data (Satellite Imagery) and evaluation techniques. In following practice, land surface temperature was subjected through spatial analysis and rise or fall in temperature was identified, distributed over the surface exposed to free the air present on every land use/land cover class.

As air temperature ranges observed in the months September and October 1931 to 2012 may be compared to land surface temperature ranges in 2011 


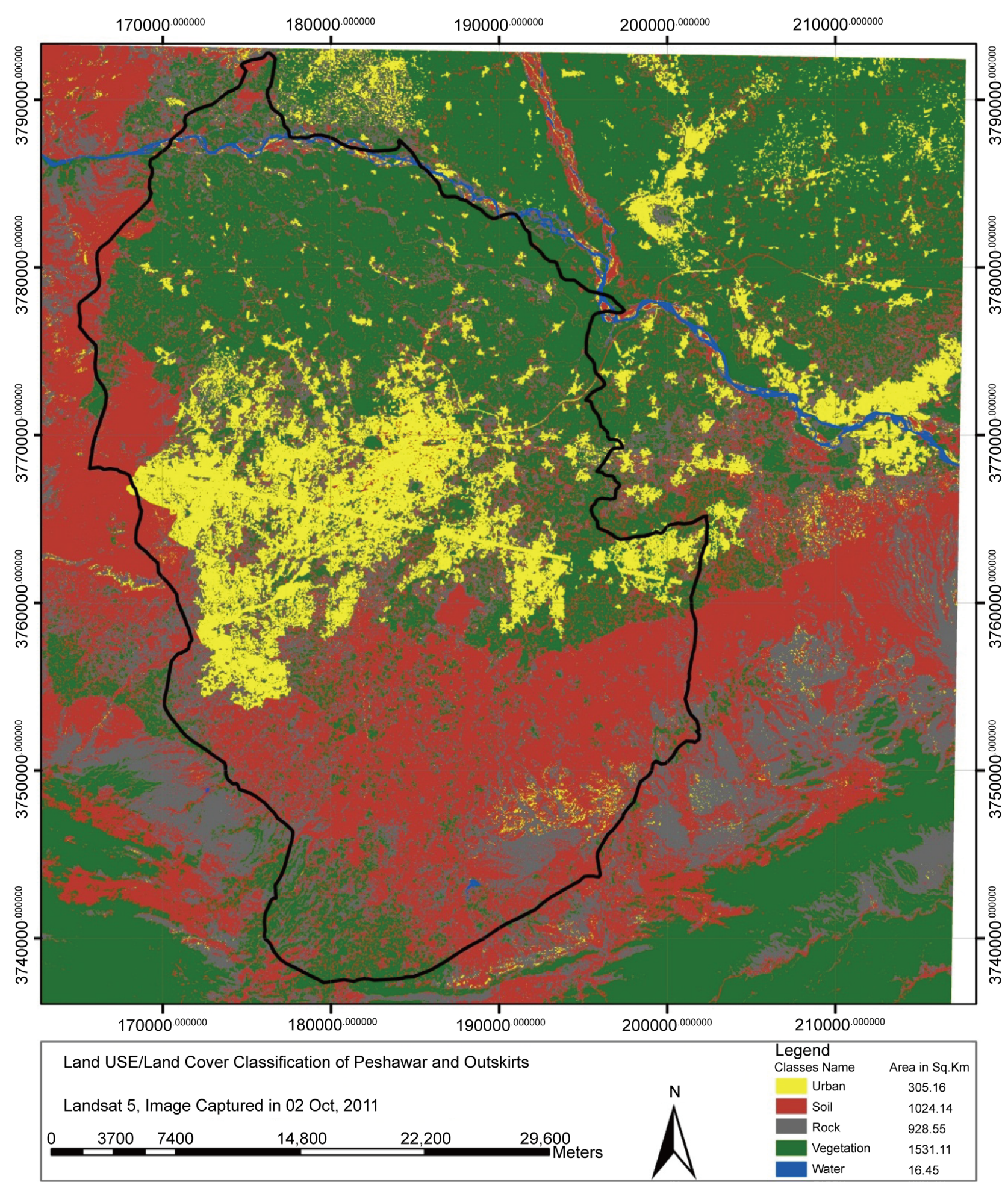

Figure 3. Derived from Landsat image from 2011 (Source: Earth Explorer).

Landsat TM imagery. It will be discussed in next figure which is Land Surface Temperature of Peshawar.

From the following images very interesting result was found as Figure 6 exhibiting. 1992 imagery in comparison to 2011 was showing less temperature 


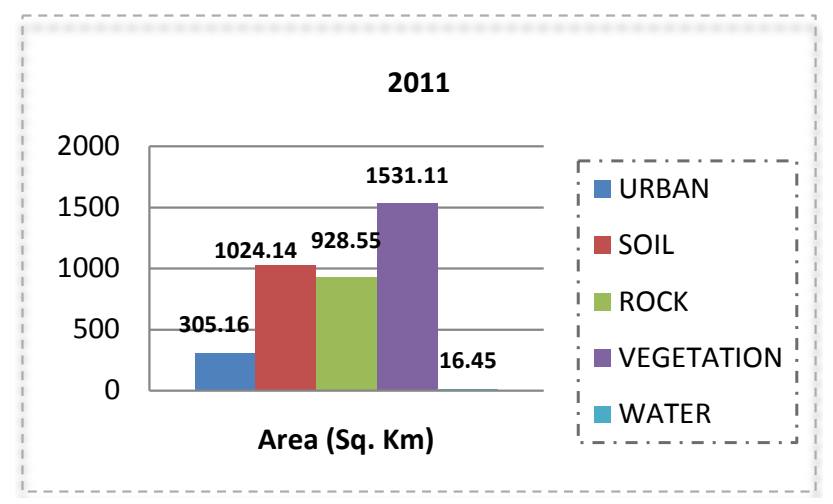

Figure 4. Land use/land cover bar graph of 2011 image.

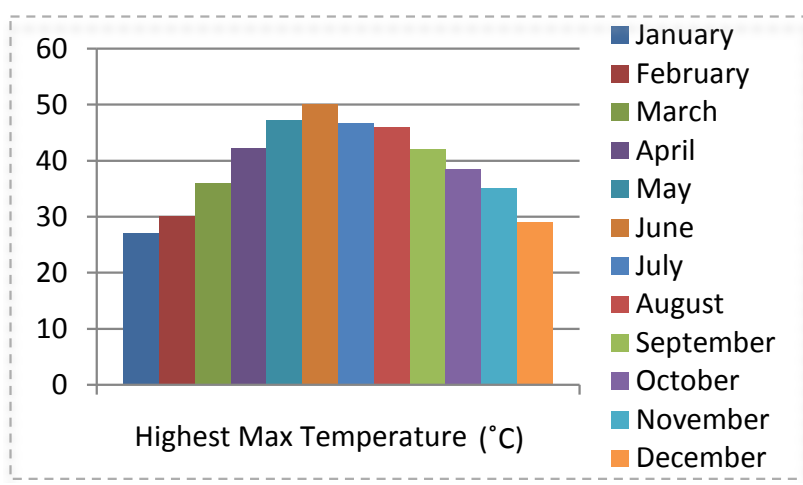

Figure 5. Highest maximum temperatures (During 1931-2012). Source: Pakistan Meteorological Department.

variation in built up. As themes suggest a sharp rise in temperature from 1 to 3 degrees in urban area and scattered parts of soil, vanishing of vegetation (Deforestation) may be accounted for this fact.

It is evident from the temperature ranges in 2011 LST imagery that the surface temperatures of an urban built up area are shifted towards high as it was in 1992 LST imagery.

\section{Urban Sprawl and Environment Linkage}

As the urban area expands it brings about the many activities like sewage, construction, transportation, deforestation, and industrialization. These factors affects directly to the local environment in terms of more exhaust to the air directly or sometimes indirectly.

As Peshawar is third fastest growing cities of Pakistan, it encompasses new housing societies, industries and colonies which are made at the cost of vegetated area in the outer part of the city. Resultantly, more greenhouse gases are added to the air, which produces not only warm and degradation in the local environment but also destroy ecosystems. It results climatic variation in local and international environment.

Transportation is another factor along with the above stated factors. It is necessary for human mobilization to earn and get a livelihood. It also adds toxic 


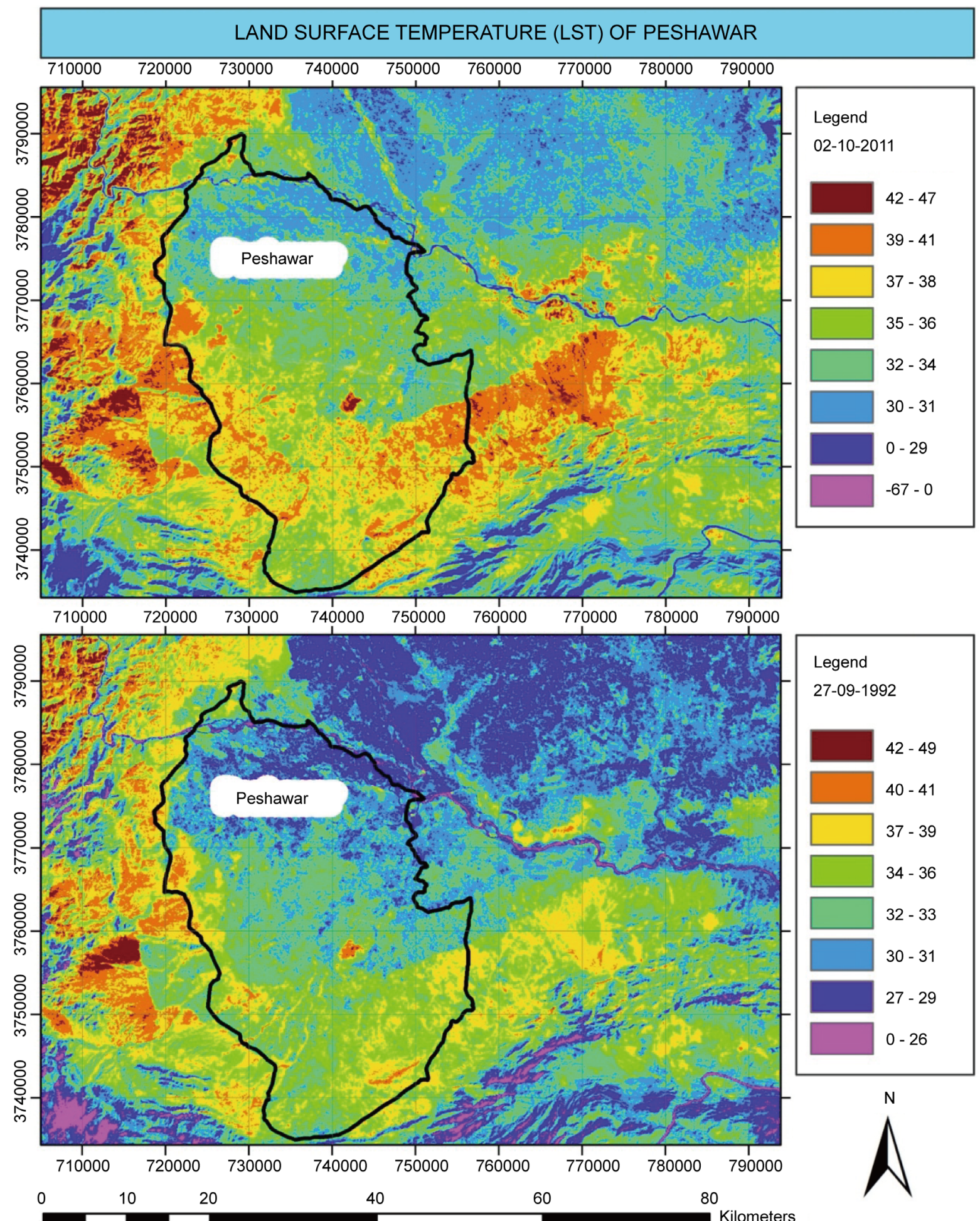

Figure 6. Derived from Landsat image of Peshawar in 1992 \& 2011 (Source: Earth Explorer).

elements to the air because it consumes fossil fuels.

\section{Conclusions}

This study draws a clear difference between two imageries in terms of tempera- 
tures in the 19 year gap. Hence urban heat island created due urban sprawl and human industrial activities. It has also unveiled the fact that the surface temperature is creeping up as time passes on.

Meteorological and climatic figures reveal that over the preceding couple of decades Peshawar and its suburbs have received extreme temperatures and sever seasons in different months. The average rainfall trend has been varied and turning out to be vegetation free urban and neighboring area.

Land surface temperature estimation also unveils these facts showing thematic temperature distribution over the land surface. The figures suggest urban temperature risen up to 1 to 3 degree last 19 years.

\section{Acknowledgements}

This is partly sponsored by urban unit, P\&D Department, Government of the Punjab. Sir Amer Mehmood associate professor in the Space Science Department assisted me technically and financially in this study.

\section{References}

[1] Ramachandra, T.V. and Kumar, U. (2009) Land Surface Temperature with Land Cover Dynamics: Multi-Resolution, Spatio-Temporal Data Analysis of Greater Bangalore. International Journal of Geoinfomatics, 5, 43-53.

[2] Gallo, K.P. and Owen, T.W. (1998) Assessment of Urban Heat Islands: A Multi-Sensor Perspective for the Dallas-Ft. Worth, USA Region. Geocarto International, 13, 35-41.

[3] Manley, G. (1958) On the Frequency of Snowfall in Metropolitan England. Quarterly Journal of the Royal Meteorological Society, 84, 70-72. https://doi.org/10.1002/qj.49708435910

[4] Rosenzweig, C., Solecki, W.D., Parshall, L., Chopping, M., Pope, G. and Goldber, R. (2005) Characterizing the Urban Heat Island in Current and Future Climates in New Jersey. Environmental Hazards, 6, 51-62. https://doi.org/10.1016/j.hazards.2004.12.001

[5] Weng, Q. (2009) Thermal Remote Sensing of Urban Climate and Environmental Studies: Methods, Applications, and Trends. ISPRS Journal of Photogrammetry and Remote Sensing, 64, 335-344. https://doi.org/10.1016/j.isprsjprs.2009.03.007

[6] Voogt, J.A. and Oke, T.R. (2003) Thermal Remote Sensing of Urban Climates. Remote Sensing of Environment, 86, 370-384.

https://doi.org/10.1016/S0034-4257(03)00079-8

[7] District Census Report Peshawar (1998) Department of Statistics Khyber Pakhtoon Khawa. http://www.worldcat.org/title/1998-district-census-report-of-peshawar

[8] Markham, B.L. and Barker, J.L. (1987) Thematic Mapper Bandpass Solar Exoatmospherical Radiances. International Journal of Remote Sensing, 8, 517-523. https://doi.org/10.1080/01431168708948658 
Submit or recommend next manuscript to SCIRP and we will provide best service for you:

Accepting pre-submission inquiries through Email, Facebook, LinkedIn, Twitter, etc. A wide selection of journals (inclusive of 9 subjects, more than 200 journals)

Providing 24-hour high-quality service

User-friendly online submission system

Fair and swift peer-review system

Efficient typesetting and proofreading procedure

Display of the result of downloads and visits, as well as the number of cited articles Maximum dissemination of your research work

Submit your manuscript at: http://papersubmission.scirp.org/

Or contact ars@scirp.org 